\title{
There's Life in the Old Dog Yet
}

Dear Reader,

No, the combustion engine is not dead, even if some interest groups would rather it were. Of course, we cannot pretend "business as usual" will last forever, with most powertrains in operation set to be hybridized within a few short years. E-fuels won't change this in any way. In the large powertrain orchestra, however, the combustion engine will remain a key instrument for meeting global mobility needs - at least in the next two to three decades. It will take at least this long to solve the fundamental infrastructure issues for sustainably managed energy and mobility provision.

However, diversifying powertrain types represents more than just challenge and uncertainty. What it also does is allow the long-since written-off fuel cell and gas drives to establish a presence in the competition for concepts - as well as e-mobility and hybridization. The aim is to reduce emissions to a level prescribed by the pollution load on intake air. Then, however, it will be high time to pursue a holistic and honest approach to $\mathrm{CO}_{2}$ emissions when it comes to providing energy and producing and disposing of powertrain systems. Domestic and international players must lose no time in ending their blindsided policies.

It makes no sense whatsoever to have gas-powered drives confined to the shadows in the powertrain mix in such a way. With their help, it would be possible to leverage considerable potential and thus improve the emissions and energy balance. Using methane from renewably generated electricity for powertrains would offer sustainability of equivalent merit to battery-electric vehicles, from the cradle-to-grave perspective. This was the main reason for dedicating the cover story of this MTZ to combustion engine technology, so often written off beforehand. But as the saying goes, there's life in the old dog yet.

I hope you enjoy reading this issue of MTZ.

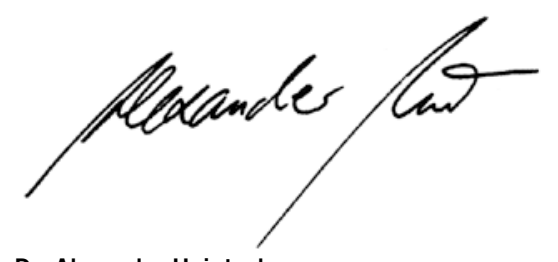

Dr. Alexander Heintzel

Editor in Chief

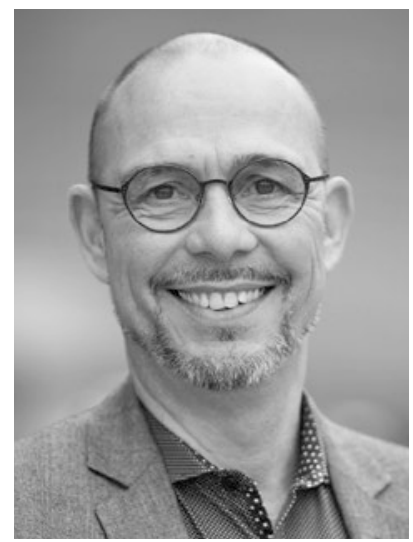

\section{lightweight.design}

NEW:

Top Magazine for Lightweight

Construction

www.lightweight-design.de

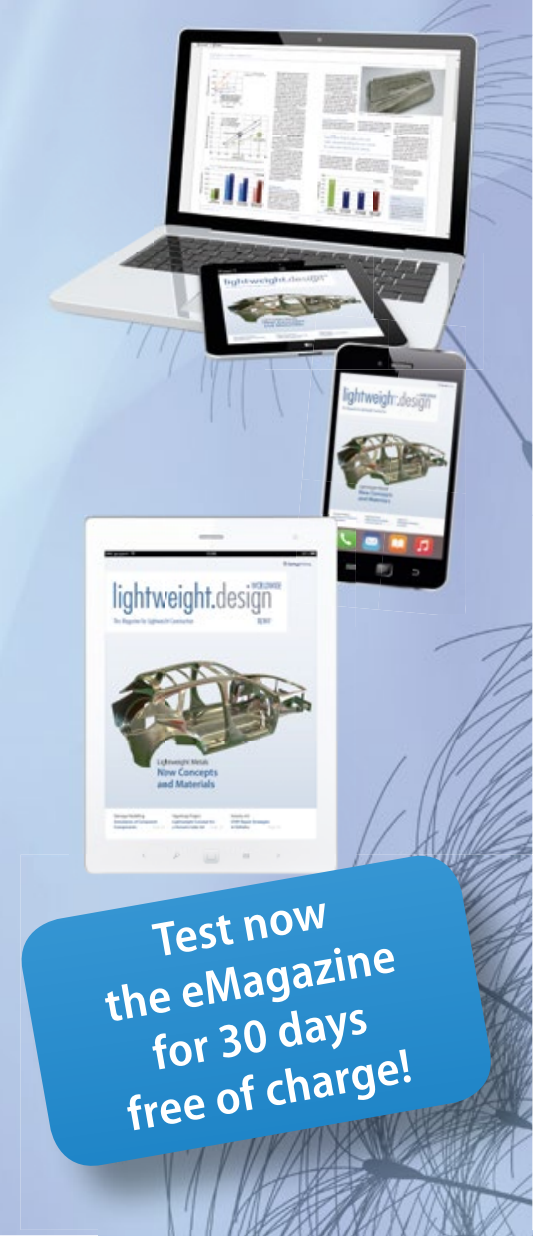

lightweight.design worldwide provides you with all the practical information you need for implementing lightweight construction principles in developing and manufacturing new products across the entire value chain.

www.my-specialized-knowledge. com/lightweightdesign 